\title{
Portföy Optimizasyonunda Markowitz Modelinin Kullanımı: Bireysel Emeklilik Yatırım Fonları Üzerine Bir Uygulama
}

\author{
Hasan Uygurtürk* \\ Turhan Korkmaz ${ }^{* *}$
}

\section{ÖZET}

Türkiye'deki kamu sosyal güvenlik sisteminin tamamlayıcısı olan bireysel emeklilik sistemi, gönüllü katılım esasına dayanmaktadır. Düzenli tasarruf yapma firsatı sunan bireysel emeklilik sisteminde tasarruflar emeklilik yatırım fonlarına aktarlmaktadır. Tasarrufların hangi fonlara aktarılacağı ise katılımcılar tarafindan belirlenmektedir. Katılımcının riske karşı tutumu ve getiri beklentisi yatırım aşamasında öne çıkmaktadır. Ekonomi ve piyasa koşulları dikkate alınarak gerektiğinde fon dă̆llımlarında değişikliğe gidilebilmektedir. Bu çalışmada Türkiye'deki mevcut ve/veya potansiyel bireysel emeklilik sistemi katılımcllarına yönelik olarak optimal portföylerin oluşturulması amaçlanmıştır. Bu amaç doğrultusunda Harry Markowitz (1952) tarafindan gelişstirilen modern portföy teorisi kapsamında işlemler gerçekleştirilmiştir. Çalışma sonucunda, getiri beklentisinin artışına bağll olarak portföylerde ağırlıklı olarak orta ve yüksek risk grubunda yer alan fonlara yatırım yapılması gerektiği tespit edilmiştir. Getiri beklentisinin düşmesi durumunda yüksek riskli emeklilik fonlarının portföydeki değerinde ise önemli bir azalma gözlemlenmiştir.

Anahtar Kelimeler: Emeklilik Fonu, Modern Portföy Teorisi, Optimal Portföy.

JEL Sinıflandırması: G11, G22.

\begin{abstract}
Use of the Markowitz Portfolio Optimization Model: An Application on the Individual Retirement Investment Funds

ABSTRACT

Individual retirement system, which is complementary to the public social security system in Turkey, is based on voluntary participation basis. Savings are transferred to pension funds in the individual retirement system offering the opportunity to make regular savings. Savings to be transferred which funds are determined by the participants. Participant's attitude to risk and return expectations comes to the forefront in the investment phase. Fund allocation can be changed taking into account economic and market conditions as needed. In this study, creating optimal portfolios are aimed for the current and/or the potential participants of the individual retirement system in Turkey. For this purpose, within the scope of modern portfolio theory developed by Harry Markowitz (1952) the process was carried out. As a result, It was determined that the funds should be invested mainly located in the medium and high-risk groups of funds depending on the expected return increase. In case of return expectations fall, it was observed a significant decrease that the rate of high-risk pension funds in the portfolio.
\end{abstract}

Keywords: Pension Funds, Modern Portfolio Theory, Optimal Portfolio.

Jel Classification: G11, G22.

\footnotetext{
*Yrd. Doç. Dr. Hasan Uygurtürk, Karabük Üniversitesi, İşletme Fakültesi, ha_uygurturk@yahoo.com

** Prof. Dr. Turhan Korkmaz, Mersin Üniversitesi, İktisadi ve İdari Bilimler Fakültesi, korktur@gmail.com
} 


\section{GíRiş}

Dünya genelindeki pek çok ülkenin mevcut sosyal güvenlik sistemlerinin tatmin edici nitelikte olmaması ülkeleri farklı arayışlar içerisine sokmaktadır. Bu durum karşısında ülke yöneticileri toplumsal yaşamın sağlıklı işleyişini sağlamak ve sürdürebilir bir yapıya kavuşmak için yapısal reformlar gerçekleştirmektedirler.

Dünyadaki çoğu ülkede olduğu gibi Türkiye'de de mevcut kamu sosyal güvenlik sistemi pek çok sorunla karşı karşıya bulunmaktadır. Bu durum kamu sosyal güvenlik sisteminin sağlıklı ve etkin işleyişini zorlaştırarak katılımcıların emeklilik dönemindeki faydalarını azaltmaktadır.

Faydası gittikçe azalan ve karşılaştığı sorunlar yüzünden verimi düşen mevcut emeklilik sistemleri önemli yapısal reformlarla iyileştirilmeye çalışılmaktadır. Dünya üzerindeki pek çok ülkede olduğu gibi Türkiye'de de gerçekleştirilen sosyal güvenlik alanındaki önemli yapısal reformlardan biri de bireysel emeklilik sisteminin hayata geçirilmesidir.

Türkiye'de bireysel emeklilik sistemi, hali hazırda yürürlükte olan kamu sosyal güvenlik sisteminin tamamlayıcısı olarak kurulmuştur. Bireylerin çalışma yaşamları boyunca yaptıkları düzenli tasarrufların yatırıma yönlendirilmesini sağlayarak oluşacak birikimlerle, tasarruf yaptıkları dönemde sahip oldukları refah seviyesinin emeklilik döneminde de devam etmesini sağlamayı amaçlayan bireysel emeklilik sistemi, gönüllü katılım esasına dayanmaktadır.

Düzenli tasarruf ve yatırım yapma firsatı sunan bireysel emeklilik sisteminde tasarrufların nasıl ve ne şekilde değerlendirileceği katılımcı tarafından belirlenmektedir. Diğer bir ifadeyle katılımcıların sisteme aktardıkları tasarruflar kendilerinin belirlediği fonlarda değerlendirilmektedir. Katılımcılar, emeklilik sözleşmesi süresi içinde fonlara aktarılan katk1 payı tutarını ve ödeme dönemini değiştirebilmektedir. Ayrıca katılımcılar yılda en fazla 6 kez fon dağılım oranı ve $4 \mathrm{kez}$ de emeklilik planı değişikliğine gidebilmektedir. Bireysel emeklilik sisteminde emekli olmak için katılımcının, sisteme ilk giriş tarihinden itibaren 10 yıl süreyle sistemde kalması ve 56 yaşını tamamlaması gerekmektedir. Emekliliğe hak kazanan katılımcı, bireysel emeklilik hesabındaki birikimlerinin bir kısmının veya tamamının defaten ödenmesini talep edebileceği gibi kendisine belirli bir süre veya ömür boyu maaş bağlanmasını talep de edebilir. Bireysel emeklilik sistemi katılımcıları, istedikleri anda emeklilik birikimlerini alarak sistemden ayrılma hakkına da sahiptirler. Sistemden ayrılan katılımcılara yapılacak ödemeler, katılımcıların sistemde kaldıkları süre boyunca yaptıkları ödeme tutarının içerdiği getiri tutarı üzerinden stopaj kesintisine tabidir (EGM, 2015a).

Emeklilik yatırımları uzun vadeli yatırımlar olduğundan, katılımcının yatırım stratejisine bağlı olarak, başlangıçta seçilen fonların getirilerinde zaman içerisinde düşüşlerin yaşanabilmesi olasılık dahilindedir. Söz konusu nedenle katılımcıların fon tercihlerini, risk seviyeleri ve getiri beklentileri doğrultusunda güncellemesi oldukça önem taşımaktadır. 
Bu çalışmada Türkiye'deki mevcut ve/veya potansiyel bireysel emeklilik sistemi katılımcılarına yönelik olarak bir yatırım stratejisi önerisinin geliştirilmesi ve bu doğrultuda optimal portföylerin oluşturulması amaçlanmıştır. Katılımcılar, emeklilik şirketi tarafından sunulan fonlar arasından tasarruflarının değerlendirileceği fon veya fonları belirlerken kendi risk toleransları ve getiri beklentileri doğrultusunda hareket etmektedirler. Dolayısıyla katılımcının riske karşı tutumu ve getiri beklentisi yatırım stratejisini oluşturmaktadır. Her ne kadar katılımcılar fonların risk ve getiri unsurlarını dikkate alarak tercih yapmaya çalışsa da pek çok katılımcı optimal fon dağılımında sıkıntı yaşayabilmektedir. Söz konusu duruma bir çözüm önerisi getirebilmek amacıyla, Markowitz (1952) tarafından geliştirilen modern portföy teorisi çalışmada temel alınmış ve kuadratik programlama aracı olan Excel çözücü (solver) yardımıyla mevcut ve/veya potansiyel katılımcılara yönelik optimal portföyler oluşturulmuştur.

\section{MODERN PORTFÖY TEORİSI}

Yatırım sürecindeki önemli unsurlardan biri portföy kararının verilmesidir. En basit ifadeyle portföy, menkul kıymetler, varlıklar veya ilgili diğer nesnelerin kombinasyonu olarak tanımlanmaktadır (Barkley vd., 2010:41). Pek çok yatırımcı portföy dağılımı kararı vereceği zaman öncelikle varlıkları hisse senetleri, devlet tahvili gibi geniş varlık sınıflarına ayırdıktan sonra fonlarını bu çeşitli varlık sınıflarına nasıl dağıtacağının kararını verir. Söz konusu süreçte yatırımcıların kullandığı varlık sınıfları "stil” ve sürecin kendisi de "yatırım stili" olarak ifade edilmektedir (Barberis ve Shleifer, 2003:162).

Harry Markowitz, 1952 yılında yayımlanan "Portfolio Selection" adlı makalesinde Ortalama Varyans Modeli ile modern portföy teorisinin temellerini atmıştır. Markowitz'in ortalama-varyans modeli yatırımları çeşitlendirme fikrinin ilk matematiksel formülü olarak kabul edilmektedir (Rubinstein, 2002:1041-1042). Model, yatırımcının hedeflediği getiri düzeyine ulaşabilmek için üstlenmesi gereken minimum risk seviyesini ve bu risk seviyesindeki portföyün yapısını tespit etmeye yardımcı olmaktadır. Başka bir ifadeyle Markowitz modelinin, hedeflenen beklenen getiri düzeyini karşılayacak minimum varyanslı portföyü bulmaya çalıştığı söylenebilir (Ulucan, 2004:1). Söz konusu portföyler, verilen (ya da daha büyük) beklenen getiri ve verilen (ya da daha az) varyans için maksimum beklenen getiriye sahiptir ve etkin portföyler olarak adlandırılmaktadırlar. Etkin portföy tarafından sağlanan beklenen getiri ve varyans, etkin ortalama-varyans kombinasyonu olarak adlandırılmaktadır. Tüm etkin ortalama-varyans kombinasyonları kümesi de "etkin sınır" olarak isimlendirilmektedir (Jacobs vd., 2005:586). Dolayısıyla beklenen getiri seviyesinde minimum risk sunan portföyler etkin sınırda yer almaktadır. Etkin sınır, her bir beklenen getiri seviyesinde, yatırımcılara paralarını değerlendirmede en iyi yolu göstermektedir (Fernández, ve Gómez, 2007:1178). 
Portföy optimizasyonunda iki temel faktör bulunmaktadır. Bunlar getiri ve risk faktörleridir. Birden fazla menkul kıymetten oluşan bir portföyün beklenen getirisinin ve riskinin bulunmasında aşağıdaki formüllerden yararlanılmaktadır (Kardiyen, 2008:338-339).

$$
\begin{aligned}
& E\left(r_{p}\right)=\sum_{i=1}^{n} E\left(r_{i}\right) x_{i} \\
& \sigma_{p}^{2}=\sum_{i=1}^{n} \sum_{j=1}^{n} \operatorname{cov}\left(r_{i}, r_{j}\right) x_{i} x_{j}
\end{aligned}
$$

Burada;

$\mathrm{x}_{\mathrm{i}}=\mathrm{i}$ menkul kıymetinin portföydeki oranını,

$\mathrm{E}\left(\mathrm{r}_{\mathrm{p}}\right)=$ portföyün beklenen getirisini,

$\sigma_{p}^{2}=$ portföy varyansını (riski),

$\mathrm{E}\left(\mathrm{r}_{\mathrm{i}}\right)=\mathrm{i}$ menkul klymetinin beklenen getirisini,

$\operatorname{cov}\left(r_{i}, r_{j}\right)=i$ ve $j$ menkul kıymetlerinin getirilerinin kovaryansını,

$\mathrm{n}=$ mevcut menkul kıymet sayısını ifade etmektedir.

Markowitz, yatırımcının amacının önceden belirlenmiş beklenen getiriyi elde ederken riskini en aza indirmek olduğunu varsaymıştır. Dolayısıyla Markowitz'in modeli, hedeflenen beklenen getiri düzeyini sağlayan minumum varyanslı (minimum riskli) portföyü bulmayı amaçlamaktadır (Crama ve Schyns, 2003:547-548). Söz konusu model aşağıda yer almaktadır.

$$
\min \sum_{i=1}^{n} \sum_{j=1}^{n} x_{i} x_{j} \sigma_{i j}
$$

Kisitlar:

$$
\begin{aligned}
& \sum_{i=1}^{n} x_{i} \mu_{i} \geq R \\
& \sum_{i=1}^{n} x=1
\end{aligned}
$$

Modelde;

$\mathrm{n}=$ mevcut varlık sayısını

$\mu_{i}=\mathrm{i}$ varlığın beklenen getirisini $(\mathrm{i}=1,2, \ldots, \mathrm{n})$

$\sigma_{i j}=\mathrm{i}$. ve j. varlıklar arasındaki kovaryans değerini,

$\mathrm{R}$ = hedeflenen beklenen getiri düzeyini,

$\mathrm{x}_{\mathrm{i}}=\mathrm{i}$. varlığın portföy içindeki oranını göstermektedir. 
Formül 3'de minimize edilmek istenen amaç fonksiyonu, formül 4'de portföyün hedeflenen beklenen getirisiyle, portföydeki her bir yatırım aracının beklenen getirisiyle portföy içindeki ağırlıklarının çarpımlarının toplamı gösterilmektedir. Formül 5'de ise yatırım araçlarının portföy içindeki ağırlıklarının toplamının 1 olduğu ifade edilmektedir.

\section{LITERATÜR ARAŞTIRMASI}

Optimal portföylerin oluşturulması araştırmacılar ve yatırımcılar arasında güncelliğini koruyan konuların başında gelmektedir. Gerçekleştirilen çeşitli çalışmalarda, portföy seçim problemi farklı yöntemler kullanılarak çözülmeye çalışılmıştır. Optimal portföylerin oluşturulması üzerine gerçekleştirilen çalışmalarda ilgi genel olarak menkul kıymet borsalarında işlem gören hisse senetleri üzerinde yoğunlaşmıştır. Dolayısıyla yatırım fonları ile ilgili olarak yapılan çalışmalara daha az rastlanmaktadır. Söz konusu çalışmalardan başlıcaları aşağıda yer almaktadır.

Sharpe (1967) çalışmasında açık uçlu yatırım fonlarının portföy seçimi için doğrusal hedef programlama modelini önermiştir. McMullen ve Strong (1998), çalışmalarında 135 hisse senedi yatırım fonunu bireysel yatırımcı bakış açısıyla analiz etmişılerdir. Çalışmada veri zarflama analizi yöntemi kullanılmış ve bu yöntemin ortalama varyans optimizasyonu yöntemine alternatif olabileceği belirtilmiştir. Araştırmacılar çalışmada ulaşılan sonuçların, yatırımcıların yatırım kararlarına yardımcı olabileceğini belirtilmiştir. Xia vd. (2001) işlem maliyetleriyle birlikte optimal portföy seçimini gerçekleştirmek için dorusal programlama algoritmasını kullanmışlardır. Parra vd. (2001) çalışmalarında İspanyol yatırım fonlarının portföye seçiminde bulanık hedef programlama yöntemini kullanmışlardır. Çalışmada bireysel yatırımcılar için optimal portföyün oluşturulmasında getiri, risk ve likidite kriterlerini dikkate almışlardır.

Oh vd. (2005), genetik algoritma kullanarak endeks fon yönetimi için portföy optimizasyonu tasarımı önermişlerdir. Çalışmada, genetik algoritma yönteminin geleneksel portföy mekanizmasına göre üstün avantajlara sahip olduğu belirtilmiştir. Chen ve Huang (2009), çalışmalarında hisse senedi yatırım fonları üzerine odaklanarak, yatırım fonlarının gelecekteki getiri oranları ve risklerinin üçgen bulanık sayılar ile temsil edildiği temel bir portföy seçim modeli önermişlerdir.

\section{METODOLOJİ VE VERİ SETI}

$\mathrm{Bu}$ çalışmada mevcut ve/veya potansiyel bireysel emeklilik sistemi katılımcılarına gerçekleştirecekleri portföy dağılımında yardımcı olabilecek optimal yatırım önerisi geliştirilmesi amaçlanmıştır. Çalışmada önerilen yatırım stratejisi şirket bazında ele alınmıştır. Türkiye'de Şubat 2015 itibariyle 19 emeklilik şirketi faaliyet göstermekle birlikte bu şirketlerin hepsinin analiz kapsamına alınarak işlem yapılmasının mümkün olmamasından dolayı, analiz kapsamına fon tutarı ve katılımcı sayısı bakımından ilk sıralarda yer alan iki emeklilik şirketi dahil edilmiştir. Söz konusu iki şirketten biri Anadolu Hayat Emeklilik A.Ş. 
ve diğeri ise Garanti Emeklilik ve Hayat A.Ş. dir. Bu iki şirket toplam fon büyüklügüunün yaklaşık \%36'sına ve katılımcı sayısının da yaklaşık \%35'ine sahip bulunmaktadır (EGM, 2015b).

Emeklilik şirketlerinin katılımcılarına sundukları her bir fonun, içerisindeki enstrümana göre türü, getirisi ve riski farklılaşmaktadır. Fonlar düşük, orta ve yüksek risk profiline uygun olarak oluşturulmaktadır. Çalışmaya, analiz kapsamına alınan emeklilik şirketlerinin düşük, orta ve yüksek riskli fon gruplarına dahil olan, analiz dönemi olarak belirlenen Ocak 2005-Aralık 2014 dönemini kapsayan 10 yıllık süreçte devamlı faaliyette bulunan, başka bir emeklilik fonuyla birleşmeyen, başka bir fon tarafından devralınmayan, tasfiye halinde olmayan ve eksiksiz veriye sahip olan fonları dahil edilmiştir.

Çalışmada kullanılan fonlara ait bilgiler aşağıda yer almaktadır.

Tablo 1: Anadolu Hayat Emeklilik A.Ş.'ye Ait Emeklilik Yatırım Fonları

\begin{tabular}{|l|l|l|}
\hline Fon Kodu & Risk Grubu & Fon Ad1 \\
\hline AH1 & Düşük & Gelir Amaçlı Kamu Borçlanma Araçları EYF* \\
\hline AH2 & Düşük & Para Piyasası Likit Esnek EYF \\
\hline AH3 & Orta & Gelir Amaçlı Birinci Kamu D1ş Borçlanma Araçları EYF \\
\hline AH6 & Orta & Büyüme Amaçlı İkinci Esnek EYF \\
\hline AH9 & Orta & Esnek EYF \\
\hline AH5 & Yüksek & Büyüme Amaçl1 Hisse Senedi EYF \\
\hline AH0 & Yüksek & Büyüme Amaçlı Esnek EYF \\
\hline
\end{tabular}

*EYF: Emeklilik Yatırım Fonu

Tablo 1' de yer alan bilgilere göre Anadolu Hayat Emeklilik A.Ş.'ye ait fonlardan 2'si düşük risk, 3’ü orta risk ve 2 adedi de yüksek risk grubunda yer almaktadır.

Tablo 2: Garanti Emeklilik ve Hayat A.Ş.’ye Ait Emeklilik Yatırım Fonları

\begin{tabular}{|l|l|l|}
\hline Fon Kodu & Risk Grubu & Fon Adı \\
\hline GED & Düşük & Gelir Amaçlı Esnek EYF* \\
\hline GEL & Düşük & Likit Esnek EYF \\
\hline GHE & Orta & Esnek EYF \\
\hline GEK & Orta & Gelir Amaçlı Kamu Borçlanma Araçları EYF \\
\hline GEU & Orta & İkinci Gelir Amaçlı Esnek EYF \\
\hline GHG & Yüksek & Gelir Amaçlı Kamu Dış Borçlanma Araçları EYF \\
\hline GEH & Yüksek & Büyüme Amaçlı Hisse Senedi EYF \\
\hline
\end{tabular}

*EYF: Emeklilik Yatırım Fonu

Tablo 2' deki Garanti Emeklilik ve Hayat A.Ş.'ye ait fonların 2'si düşük risk, 3'ü orta risk ve 2 adedi de yüksek risk grubunda bulunmaktadır.

Tablo 1 ve 2'de yer alan fonların analiz işlemlerinde 10 yıllık analiz dönemi 2'şer aylık alt dönemlere ayrılmış ve söz konusu fonlara ait getiriler 2 aylık olarak hesaplanmıştır. Getirilerin 2 aylık hesaplanmasının temel nedeni bireysel emeklilik sisteminde katılımciların fon dağılımlarını yılda en fazla 6 kez değiştirebilmeleridir. İlgili yasal kısıtlamadan dolayı katılımcılar yılda ortalama 2 ayda bir dağılım değişikliğine gidebildiğinden çalışmada söz 
konusu kısıt dikkate alınarak getiriler hesaplanmıştır. Toplam 60 alt döneme ilişkin fon getirilerinin hesaplanmasında kullanılan veriler Sermaye Piyasası Kurulu'nun (SPK) resmi internet sayfalarından alınmıştır (SPK, 2015). Çalışma kapsamına alınan fonların 2 aylık getirileri aşağıdaki formül kullanılarak hesaplanmıştır.

$$
\begin{aligned}
& \mathrm{Ri}=\ln (\mathrm{Rt} / \mathrm{Rt}-2) \\
& \mathrm{Ri} \quad=\mathrm{i} \text { fonunun } 2 \text { aylık logaritmik getirisini, } \\
& \mathrm{Rt} \quad=\mathrm{i} \text { fonunun } \mathrm{t} \text { dönemindeki ay başı fiyatını, } \\
& \mathrm{Rt}-1=\mathrm{i} \text { fonunun } \mathrm{t}-2 \text { dönemindeki ay sonu fiyatını göstermektedir. }
\end{aligned}
$$

Analiz işlemlerinde, iki farklı şirkete ait farklı risk gruplarında yer alan fonlarla belirli bir getiri beklentisi altında oluşturulması muhtemel optimal portföy dağılımlarının tespit edilmesi hedeflenmiştir.

\section{BULGULAR}

Çalışma kapsamında ayrı ayrı ele alınan her iki emeklilik şirketi ve bunlara ait toplam 14 fondan oluşan bir yatırım uzayı için Markowitz portföy seçim modeli kullanılmıştır. Çözüm ortamı olarak bir elektronik hesap tablosu yazılımı olan Microsoft Excel ve Excel eklentisi olan “Çözücü” (Solver) fonksiyonu kullanılmıştır.

Markowitz'in Optimal Portföy teoremi doğrultusunda oluşturulacak optimal emeklilik fon dağılımı için izlenen süreç aşağıda yer almaktadır. Buna göre Anadolu Hayat Emeklilik A.Ş.'ye ait fonların analiz dönemine ilişkin istatiski bilgileri Tablo 3'de yer almaktadır.

Tablo 3: Anadolu Hayat Emeklilik A.Ş.'ye Ait Emeklilik Yatırım Fonlarının Ocak 2005- Aralık 2014 Dönemindeki İstatistiki Bilgileri

\begin{tabular}{|c|c|c|c|}
\hline Risk Grubu & Fon Kodu & Ortalama Getiri (2 aylı) & Standart Sapma (2 aylik) \\
\hline \multirow{3}{*}{ Düşük } & AH1 & 0,017552 & 0,020048 \\
\cline { 2 - 4 } & AH2 & 0,014996 & 0,006733 \\
\hline \multirow{3}{*}{ Orta } & AH3 & 0,018604 & 0,034614 \\
\cline { 2 - 4 } & AH6 & 0,015864 & 0,037763 \\
\cline { 2 - 4 } & AH9 & 0,019329 & 0,044939 \\
\hline \multirow{2}{*}{ Yüksek } & AH5 & 0,022405 & 0,120817 \\
\cline { 2 - 4 } & AH0 & 0,024241 & 0,071700 \\
\hline
\end{tabular}

Markowitz modeli ile portföy çeşitlendirmesi yapılırken, korelasyon katsayıları esas alınmaktadır. Bunun nedeni, korelasyon katsayısı ile portföy riski arasında doğrusal bir ilişkinin varlığıdır. Çalışmada analiz kapsamına alınan Anadolu Hayat Emeklilik A.Ş.'ye ait fonların korelasyon katsayıları Tablo 4'de yer almaktadır. 
Tablo 4: Anadolu Hayat Emeklilik A.Ş.'ye Ait Emeklilik Yatırım Fonları Arasındaki Korelasyon Katsayıları

\begin{tabular}{cccccccc}
\hline Fon Kodu & AH1 & AH2 & AH3 & AH6 & AH9 & AH5 & AH0 \\
\hline AH1 & 1 & & & & & & \\
AH2 & 0,48187 & 1 & & & & & \\
AH3 & $-0,12532$ & $-0,14960$ & 1 & & & & \\
AH6 & $-0,55936$ & $-0,23506$ & 0,40426 & 1 & & & \\
AH9 & 0,76798 & 0,16816 & $-0,23425$ & $-0,37510$ & 1 & & \\
AH5 & 0,58761 & $-0,00927$ & $-0,30828$ & $-0,31528$ & 0,94727 & 1 & \\
AH0 & 0,65835 & 0,16922 & $-0,26664$ & $-0,28603$ & 0,96864 & 0,94019 & 1 \\
\hline
\end{tabular}

Portföy optimizasyonu yapılırken korelasyon katsayısının +1'e yakın olmamasına dikkat edilmelidir. Çünkü çeşitlendirmenin etkinliği fonlar arasında yüksek korelasyon olduğunda azalış göstermektedir.

Portföy optimizasyonunun gerçekleştirilmesi için fonlar arasındaki varyans ve kovaryans değerlerinin bilinmesine ihtiyaç duyulmaktadır. Anadolu Hayat Emeklilik A.Ş.'nin fonlarına ait ilgili değerler Tablo 5'de yer almaktadır.

Tablo 5: Anadolu Hayat Emeklilik A.Ş.'ye Ait Emeklilik Yatırım Fonlarının VaryansKovaryans Değerleri

\begin{tabular}{crrrrrrr}
\hline Fon Kodu & AH1 & AH2 & AH3 & AH6 & AH9 & AH5 & AH0 \\
\hline AH1 & 0,00040 & 0,00006 & $-0,00009$ & $-0,00042$ & 0,00068 & 0,00140 & 0,00093 \\
AH2 & 0,00006 & 0,00004 & $-0,00003$ & $-0,00006$ & 0,00005 & $-0,00001$ & 0,00008 \\
AH3 & $-0,00009$ & $-0,00003$ & 0,00118 & 0,00052 & $-0,00036$ & $-0,00127$ & $-0,00065$ \\
AH6 & $-0,00042$ & $-0,00006$ & 0,00052 & 0,00140 & $-0,00063$ & $-0,00141$ & $-0,00076$ \\
AH9 & 0,00068 & 0,00005 & $-0,00036$ & $-0,00063$ & 0,00199 & 0,00506 & 0,00307 \\
AH5 & 0,00140 & $-0,00001$ & $-0,00127$ & $-0,00141$ & 0,00506 & 0,01435 & 0,00801 \\
AH0 & 0,00093 & 0,00008 & $-0,00065$ & $-0,00076$ & 0,00307 & 0,00801 & 0,00506 \\
\hline
\end{tabular}

Tablo 5'deki varyans-kovaryans matrisinin diagonalindeki değerler varlıkların varyanslarını, diğer değerler ise varlıklar arasındaki kovaryans değerlerini vermektedir.

Markowitz modelinin iki temel unsuru olan beklenen getiri ve varyans-kovaryans değerleri hesaplandıktan sonra hedeflenen farklı getiri seviyeleri için söz konusu olacak risk düzeyleri belirlenmiştir. Çalışmanın bu aşamasında Excel çözücü fonksiyonu kullanılarak portföyün riskinin (varyansının) minimize edilmesi gerçekleştirilmiştir.

Çözücü, verilen kısıtlar altında bir amaç işlevini belirli değişkenler için çözümünü sağlamaktadır. Çözücü ile n. dereceden bir bilinmeyenli denklem çözülebileceği gibi $n$ bilinmeyenli $\mathrm{m}$ adet denklem sistemini de çözmek olanaklı olmaktadır (Alan ve Yeşilyurt; 2004:156). Excel çözücü bir hücrenin maksimum ve minimum değerini belirlerken diğer hücreleri değiştirerek işlemi gerçekleştirmektedir (Ali ve Ruddock, 2000:81). 
Model ve kısıtlar Excel çözücüde tanımlandıktan sonra portföy seçim modeli optimize edilmiştir. Farklı beklenen getiri düzeyleri için oluşturulan model tekrardan çalıştırıldığında, her biri belirlenen getiri düzeyi için etkin olan portföyler elde edilecektir. Hedeflenen getiri düzeyleri ve o getiri düzeyinde ulaşılan etkin portföylerin standart sapmaları beklenen getiristandart sapma grafiği üzerinde gösterildiğinde, bu etkin portföyleri birleştiren eğri etkin sınır olarak isimlendirilmektedir (Ulucan, 2004:25). Beklenen getiriler, Excel çözücü ile çözümü sağlanan portföyler için geçerli olan en düşük ve en yüksek getiri aralığında yer alan getirilerden oluşmaktadır. En düşük ve en yüksek getiriler arasındaki farklı getiri düzeyleri için etkin portföy kombinasyonları ve portföy standart sapmaları Tablo 6'da yer almaktadır.

Tablo 6: Anadolu Hayat Emeklilik A.Ş.'ye Ait Emeklilik Yatırım Fonlarının Farklı Beklenen Getiri Düzeylerine İlişkin Portföy Ağırlıkları

\begin{tabular}{|c|c|c|c|c|c|c|c|c|}
\hline \multirow[b]{3}{*}{$\begin{array}{l}\text { Hedeflenen } \\
\text { Getiri }\end{array}$} & \multirow{3}{*}{$\begin{array}{c}\text { Risk Grubu } \\
\text { Portföyün } \\
\text { Standart } \\
\text { Sapması } \\
\end{array}$} & \multicolumn{7}{|c|}{ Fonların Portföy Ağırlıkları } \\
\hline & & \multicolumn{2}{|c|}{ Düşük } & \multicolumn{3}{|c|}{ Orta } & \multicolumn{2}{|c|}{ Yüksek } \\
\hline & & AH1 & AH2 & AH3 & AH6 & AH9 & AH5 & AHO \\
\hline $1,50 \%$ & 0,0066 & 0,00 & 1,00 & 0,00 & 0,00 & 0,00 & 0,00 & 0,00 \\
\hline $1,60 \%$ & 0,0071 & 0,13 & 0,67 & 0,09 & 0,08 & 0,00 & 0,00 & 0,03 \\
\hline $1,70 \%$ & 0,0105 & 0,31 & 0,35 & 0,16 & 0,12 & 0,00 & 0,00 & 0,06 \\
\hline $1,80 \%$ & 0,0147 & 0,49 & 0,04 & 0,23 & 0,15 & 0,00 & 0,00 & 0,09 \\
\hline $1,90 \%$ & 0,0196 & 0,34 & 0,00 & 0,38 & 0,10 & 0,00 & 0,00 & 0,18 \\
\hline $2,00 \%$ & 0,0252 & 0,16 & 0,00 & 0,52 & 0,03 & 0,00 & 0,00 & 0,29 \\
\hline $2,10 \%$ & 0,0314 & 0,00 & 0,00 & 0,57 & 0,00 & 0,00 & 0,00 & 0,43 \\
\hline $2,20 \%$ & 0,0413 & 0,00 & 0,00 & 0,40 & 0,00 & 0,00 & 0,00 & 0,60 \\
\hline $2,30 \%$ & 0,0539 & 0,00 & 0,00 & 0,22 & 0,00 & 0,00 & 0,00 & 0,78 \\
\hline $2,40 \%$ & 0,0677 & 0,00 & 0,00 & 0,04 & 0,00 & 0,00 & 0,00 & 0,96 \\
\hline
\end{tabular}

Tablo 6'daki model sonuçlarına göre 2 aylık bir zaman periyodunda \%2 getiri hedefleyen bir yatırımc1, elindeki tasarruf değerinin \%16'sını AH1 fonuna, \%52'sini AH3 fonuna, \%3’ünü AH6 fonuna ve \%29'unu da AH0 fonuna yatırmalıdır. Bu şekilde oluşacak olan portföyün standart sapması da 0,0252 olarak minimize edilmiştir. Getiri beklentisinin yükselmesi durumunda yüksek riskli emeklilik fonlarının portföydeki oranında önemli bir artış gözlemlenmiştir. Farklı getiri düzeyleri için geçerli olan portföy standart sapmalarının grafik üzerindeki gösterimiyle oluşan etkin sınır Grafik 1'de yer almaktadır. 
Grafik 1: Anadolu Hayat Emeklilik A.Ş.'nin Emeklilik Yatırım Fonlarına Ait Etkin Sinir

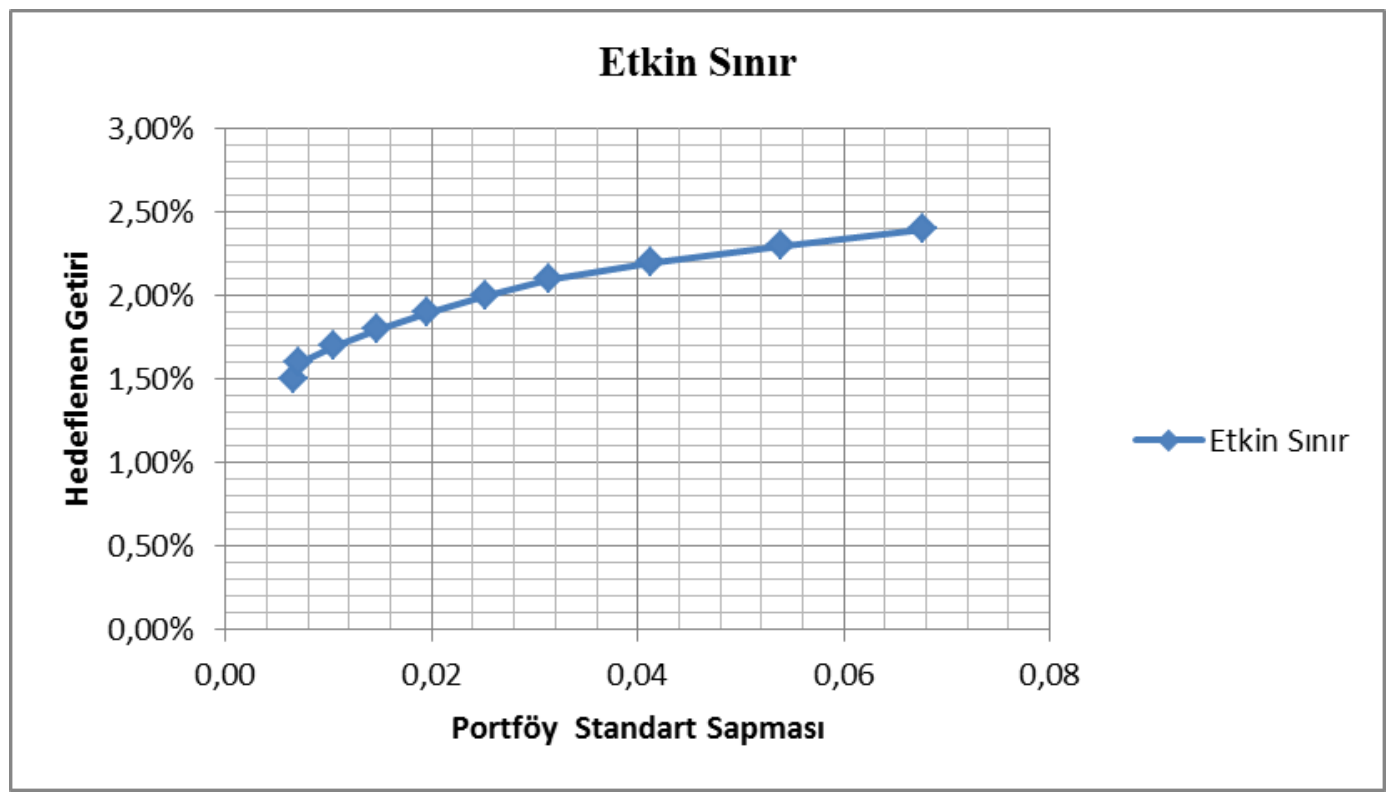

Grafik 1'deki etkin sınır üzerindeki noktalar verilen bir getiri için minimum risk değerini sunmaktadır. Diğer bir ifadeyle eğrinin üzerindeki tüm portföyler eğrinin sağında kalan portföylere göre daha baskındır.

Anadolu Hayat Emeklilik A.Ş.'ye ait fonlar için optimal portföy bileşimleri tespit edildikten sonra Garanti Emeklilik ve Hayat A.Ş. fonlarına ilişkin optimal portföy dağılımları belirlenmiştir. Söz konusu analize ilişkin bilgiler aşağıda yer almaktadır.

Tablo 7: Garanti Emeklilik ve Hayat A.Ş.'ye Ait Emeklilik Yatırım Fonlarının Ocak 2005-Aralık 2014 Dönemindeki İstatistiki Bilgileri

\begin{tabular}{|c|c|c|c|}
\hline Risk Grubu & Fon Kodu & Ortalama Getiri (2 aylı) & Standart Sapma (2 aylık) \\
\hline \multirow{3}{*}{ Düşük } & GED & 0,012452 & 0,041796 \\
\cline { 2 - 4 } & GEL & 0,016034 & 0,006739 \\
\hline \multirow{3}{*}{ Orta } & GHE & 0,017118 & 0,045625 \\
\cline { 2 - 4 } & GEK & 0,017618 & 0,021534 \\
\cline { 2 - 4 } & GEU & 0,014541 & 0,052542 \\
\hline \multirow{2}{*}{ Yüksek } & GHG & 0,018820 & 0,036705 \\
\cline { 2 - 4 } & GEH & 0,019793 & 0,118068 \\
\hline
\end{tabular}

Tablo 7'deki bilgilerden Garanti Emeklilik ve Hayat A.Ş.'ye ait 7 fonun analiz kapsamına alındığı görülmektedir. Analize dahil edilen Garanti Emeklilik ve Hayat A.Ş.'ye ait fonların korelasyon katsayıları Tablo 8'de ve varyans-kovaryans değerleri ise Tablo 9'da yer almaktadir. 
Tablo 8: Garanti Emeklilik ve Hayat A.Ş.'ye Ait Emeklilik Yatırım Fonları Arasındaki Korelasyon Katsayıları

\begin{tabular}{cccccccc}
\hline Fon Kodu & GED & GEL & GHE & GEK & GEU & GHG & GEH \\
\hline GED & 1 & & & & & & \\
GEL & $-0,06566$ & 1 & & & & & \\
GHE & $-0,58481$ & 0,10762 & 1 & & & & \\
GEK & $-0,38281$ & 0,47483 & 0,69933 & 1 & & & \\
GEU & 0,84216 & $-0,08677$ & $-0,75762$ & $-0,50920$ & 1 & & \\
GHG & 0,57350 & $-0,09857$ & $-0,20028$ & 0,00988 & 0,61529 & 1 & \\
GEH & $-0,58835$ & $-0,06292$ & 0,95395 & 0,51287 & $-0,76470$ & $-0,23898$ & 1 \\
\hline
\end{tabular}

Tablo 9: Garanti Emeklilik ve Hayat A.Ş.'ye Ait Emeklilik Yatırım Fonlarının Varyans-Kovaryans Değerleri

\begin{tabular}{cccccccc}
\hline Fon Kodu & GED & GEL & GHE & GEK & GEU & GHG & GEH \\
\hline GED & 0,00172 & $-0,00002$ & $-0,00110$ & $-0,00034$ & 0,00182 & 0,00087 & $-0,00286$ \\
GEL & $-0,00002$ & 0,00004 & 0,00003 & 0,00007 & $-0,00003$ & $-0,00002$ & $-0,00005$ \\
GHE & $-0,00110$ & 0,00003 & 0,00205 & 0,00068 & $-0,00179$ & $-0,00033$ & 0,00505 \\
GEK & $-0,00034$ & 0,00007 & 0,00068 & 0,00046 & $-0,00057$ & 0,00001 & 0,00128 \\
GEU & 0,00182 & $-0,00003$ & $-0,00179$ & $-0,00057$ & 0,00271 & 0,00117 & $-0,00466$ \\
GHG & 0,00087 & $-0,00002$ & $-0,00033$ & 0,00001 & 0,00117 & 0,00132 & $-0,00102$ \\
GEH & $-0,00286$ & $-0,00005$ & 0,00505 & 0,00128 & $-0,00466$ & $-0,00102$ & 0,01371 \\
\hline
\end{tabular}

Model ve kısıtlar Garanti Emeklilik ve Hayat A.Ş.'ye ait fonların optimizasyonu için Excel çözücüde tanımlandıktan sonra portföy seçim modeli optimize edilmiştir. Tablo 10'da farklı getiri düzeyleri için etkin portföy kombinasyonları ve portföy standart sapmaları yer almaktadır.

Tablo 10: Garanti Emeklilik ve Hayat A.Ş.'ye Ait Emeklilik Yatırım Fonlarının Farklı Beklenen Getiri Düzeylerine İlişkin Portföy Ağırlıkları

\begin{tabular}{|c|c|c|c|c|c|c|c|c|}
\hline \multirow[b]{3}{*}{$\begin{array}{l}\text { Hedeflenen } \\
\text { Getiri }\end{array}$} & \multirow{3}{*}{$\begin{array}{c}\text { Risk Grubu } \\
\text { Portföyün } \\
\text { Standart } \\
\text { Sapmas1 } \\
\end{array}$} & \multicolumn{7}{|c|}{ Fonların Portföy Ağırlıkları } \\
\hline & & \multicolumn{2}{|c|}{ Düşük } & \multicolumn{3}{|c|}{ Orta } & \multicolumn{2}{|c|}{ Yüksek } \\
\hline & & GED & GEL & GHE & GEK & GEU & GHG & GEH \\
\hline $1,40 \%$ & 0,0220 & 0,63 & 0,16 & 0,21 & 0,00 & 0,00 & 0,00 & 0,00 \\
\hline $1,50 \%$ & 0,0117 & 0,32 & 0,56 & 0,12 & 0,00 & 0,00 & 0,00 & 0,00 \\
\hline $1,60 \%$ & 0,0060 & 0,01 & 0,89 & 0,00 & 0,00 & 0,07 & 0,00 & 0,03 \\
\hline $1,70 \%$ & 0,0103 & 0,00 & 0,59 & 0,00 & 0,18 & 0,00 & 0,21 & 0,02 \\
\hline $1,80 \%$ & 0,0185 & 0,00 & 0,07 & 0,00 & 0,54 & 0,00 & 0,37 & 0,02 \\
\hline $1,90 \%$ & 0,0323 & 0,00 & 0,00 & 0,00 & 0,00 & 0,00 & 0,82 & 0,18 \\
\hline
\end{tabular}


Tablo 10'daki model sonuçlarına göre 2 aylı bir zaman periyodunda \%1,80 getiri hedefleyen bir yatırımc1, elindeki tasarruf değerinin \%7'sini GEL fonuna, \%54'ünü GEK fonuna, \%37’sini GHG fonuna ve \%2'ünü GEH fonuna yatırmalıdır. Bu şekilde oluşacak olan portföyün standart sapması da 0,0185 olarak minimize edilmiştir. Tablo 10'daki bilgilere göre getiri beklentisi yükseldikçe portföyde orta ve yüksek riskli fonların payı artış göstermektedir. \%1,90 hedeflenen getiri seviyesinde portföyde sadece yüksek riskli fonlar yer almaktadır. Farklı getiri düzeyleri için geçerli olan portföy standart sapmalarının grafik üzerindeki gösterimiyle oluşan etkin sınır Grafik 2'de yer almaktadır.

Grafik 2: Garanti Emeklilik ve Hayat A.Ş.'nin Emeklilik Yatırım Fonlarına Ait Etkin Sınır

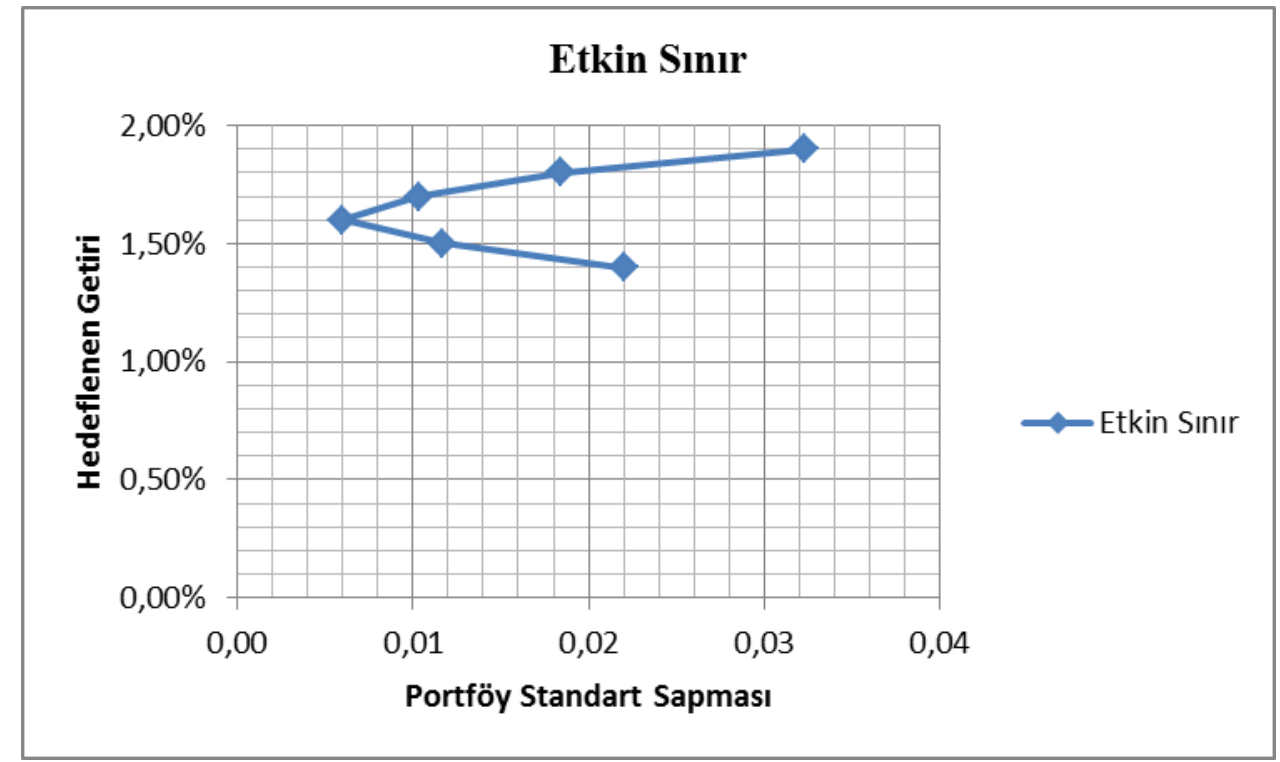

Grafik 2'deki eğri, mevcut ve/veya potansiyel katılımcılara yatırım yapmayı tercih edecekleri firsatları sunmaktadır. Buna göre eğri üzerindeki noktalarda yer alan portföyler eğrinin sağındaki diğer portföylere oranla daha baskın bir konumda bulunmaktadır.

\section{SONUÇ}

Bireysel emeklilik sisteminde her katılımcıya risk ve getiri beklentilerine uygun olarak çeşitli emeklilik fonlarına yatırım yapma imkanı sunulmaktadır. Katılımcıların gerektiğinde fon dağılımlarında değişikliğe gitmesi birikimlerinin değerlenmesi açısından önem taşımaktadır.

Bu çalışmada Türkiye'deki mevcut ve/veya potansiyel bireysel emeklilik sistemi katılımcılarına yönelik olarak bir yatırım stratejisi önerisinin geliştirilmesi ve bu sayede optimal portföylerin oluşturulması amaçlanmıştır. Bireysel emeklilik sisteminde fon tercihi katılımcının özgür iradesine bırakıldığından pek çok katılımcı fon seçim aşamasında sıkıntı yaşayabilmektedir. Dolayısıyla bu çalışmada, mevcut ve/veya potansiyel katılımcıların belirli getiri seviyelerinde karşılaşacakları risk düzeyi ile ağırlıklı olarak hangi risk grubundaki 
fonlara yatırım yapmalarının uygun olacağı belirlenmeye çalışılmıştır. Analiz işlemlerinin gerçekleştirilmesinde Markowitz tarafından geliştirilen modern portföy teorisi modeli ve kuadratik programlama aracı olan Excel çözücü (solver) kullanılmıştır.

Çalışmaya Türkiye'de faaliyet gösteren, bireysel emeklilik sisteminde katılımcı ve fon büyüklüğü açısından ilk sıralarda yer alan iki şirket dahil edilmiştir. Türkiye'de faaliyet gösteren bireysel emeklilik şirketi sayısının fazla olması ve bu şirketlere ait fonların tümünün çalışmaya dahil edilerek işlem yapılmasının mümkün olmaması çalışmanın kısıtını oluşturmuştur.

Çalışma sonucunda, getiri beklentisinin artışına bağlı olarak portföylerde daha çok orta ve yüksek risk grubunda yer alan fonlara yatırım yapılması gerektiği tespit edilmiştir. Getiri beklentisinin düşmesi durumunda yüksek riskli emeklilik fonlarının portföydeki değerinde ise önemli bir azalma gözlemlenmiştir. Söz konusu durumlar her iki şirket içinde geçerli olmaktadır. Her iki şirketin fonları için optimal portföyler dikkate alındığında, incelenen analiz döneminde, aynı getiri seviyelerinde genel olarak Anadolu Hayat Emeklilik A.Ş.'nin fonlarından oluşturulan optimal portföylerin, Garanti Emeklilik ve Hayat A.Ş.'nin fonlarından oluşturulan optimal portföylere göre daha düşük standart sapmaya sahip olduğu tespit edilmiştir.

Elde edilen sonuçlar mevcut ve/veya potansiyel katılımcıların getiri beklentilerini arttırmaları karşısında genel olarak risk seviyelerini de arttırmalarını gerekli kılmaktadır. Ancak yüksek risk üstlenmenin olumsuz sonuçlarının olacağı bilgisinin de göz önünde bulundurulması yatırım verimliliği açısından hayati önem taşımaktadır.

Analiz işlemlerinde her iki şirketin çeşitli risk gruplarında yer alan fonlarının belirli getiri düzeylerinde ön plana çıktığı belirlenmekle birlikte, söz konusu fonların gelecekte de aynı konumlarını sürdüreceği garantisinin verilmesi mümkün olamamaktadır. Analiz döneminde elde edilen sonuçlar ilgili dönem aralığı için önem arz etmektedir. Değisşen zaman aralıklarında fonların getiri ve risk seviyelerinde değişiklik söz konusu olacağından oluşturulan optimal portföylerde de farkl1lıklar olabilecektir.

Çalışmada ulaşılan sonuçlar bireysel emeklilik sistemine ilgi duyan kişiler ve katılımcılar açısından fon yatırımı konusunda ek bilgi kaynağı niteliği taşımaktadır. Kullanılan yöntemin farklı şirketlerin fonlarına da uygulanabilir olması nedeniyle, zaman içinde katılımcıların veya araştırmacıların kendi ya da diğer şirketlerin fonlarını benzer şekilde analiz etmeleri mümkün olabilecektir. 


\section{KAYNAKLAR}

Alan, Mehmet Ali - Yeşilyurt, Cavit (2004), "Doğrusal Programlama Problemlerinin Excel ile Çözümü”, C.Ü. İktisadi ve İdari Bilimler Dergisi, Cilt: 5, Sayı: 1, s. 151-162.

Ali, Hishamuddin Mohd - Ruddock, Les (2000), "The Impact of Portfolio Strategy on The 'Style' Performance of U.K. Property Companies”, Journal of Financial Management of Property and Construction, Vol. 5, No. 3, s. 79-84.

Barberis, Nicholas - Shleifer, Andrei (2003), "Style Investing”, Journal of Financial Economics, 68, s. 161-199.

Barkley, Andrew. - Peterson, Hikaru Hawana. - Shroyer, James (2010), "Wheat Variety Selection to Maximize Returns and Minimize Risk: An Application of Portfolio Theory”, Journal of Agricultural and Applied Economics, Vol. 42, Issue: 1, s. 39-55.

Chen, Liang-Hsuan - Huang, Lindsay (2009), "Portfolio Optimization of Equity Mutual Funds with Fuzzy Return Rates and Risks”, Expert Systems with Applications, Vol. 36, Issue: 2, s. 3720-3727.

Crama Y. - Schyns, Michael (2003), “Simulated Annealing for Complex Portfolio Selection Problems”, European Journal of Operational Research, 150, s. 546-571.

EGM (2015a), Bireysel Emeklilik Sistemi (BES) Hakkında http://www.egm.org.tr/?sid=69 (12.01.2015).

EGM (2015b), Emeklilik Şirketleri, http://www.egm.org.tr/?pid=350, (10.02.2015).

Fernández, Alberto - Gómez, Sergio (2007), “Portfolio Selection Using Neural Networks”, Computers \& Operations Research, 34, s. 1177-1191.

Jacobs, Bruce I.- Levy, Kenneth N. - Markowitz, Harry (2005), "Portfolio Optimization With Factors, Scenarios, and Realistic Short Positions”, Operations Research, Vol. 53, No. 4, s. 586-599.

Kardiyen, Filiz (2008), "Portföy Optimizasyonunda Ortalama Mutlak Sapma Modeli ve Markowitz Modelinin Kullanımı ve İMKB Verilerine Uygulanması”, Süleyman Demirel Üniversitesi İktisadi ve İdari Bilimler Fakültesi Dergisi, Cilt: 13, Sayı: 2, s. 335-350.

Markowitz, Harry (1952), “Portfolio Selection”, Journal of Finance, 7, s. 77-91.

McMullen, Patrick R. - Strong, Robert A. (1998), “Selection of Mutual Funds Using Data Envelopment Analysis”, Journal of Business and Economic Studies, Vol. 4, No. 1, s. $1-12$.

Oh, Kyong Joo - Kim, Tae Yoon - Min, Sungky (2005), “Using Genetic Algorithm to Support Portfolio Optimization for Index Fund Management”, Expert Systems with Applications, Vol. 28, Issue: 2, s. 371-379. 
Parra, M. Arenas - Terol, A. Bilbao - Uria, M. V. Rodriguez (2001), “A Fuzzy Goal Programming Approach to Portfolio Selection”, European Journal of Operational Research, Vol. 133, Issue: 2, s. 287-297.

Rubinstein, Mark (2002), “Markowitz’s "Portfolio Selection”: A Fifty-Year Retrospective”, The Journal of Finance, Vol. LVII, No. 2, s. 1041-1045.

Sharpe, William F. (1967), “A Linear Programming Algorithm for A Mutual Fund Portfolio Selection”, Management Science, Vol. 13, No. 7, s. 499-510.

SPK (2015), http://www.spk.gov.tr, (10.01.2015).

Ulucan, Aydın (2004), Portföy Optimizasyonu- Kuadratik Programlama Tabanlı Modelleme, Siyasal Kitabevi, Ankara.

Xia, Yusen- Wang, Shouyang- Deng, Xiaotie (2001), “A Compromise Solution to Mutual Funds Portfolio Selection with Transaction Costs”, European Journal of Operational Research, Vol. 134, Issue: 3, s. 564-581. 
